\title{
Cigarette Smoking and Cessation Perception in Student Popula- tion in India: An E-Survey
}

Renu B Pattanshetty *1, Lawrence Victor Fernandes 2, Saish Sachin Nabar ${ }^{3}$, Neha Anil Yadav ${ }^{4}$.

${ }^{*}$ Professor and Head, Department of Oncology Physiotherapy, KAHER Institute of Physiotherapy, Belagavi-590010, Karnataka, India.

${ }^{2-4}$ KAHER Institute of Physiotherapy, Belagavi-590010, Karnataka, India.

\section{ABSTRACT}

Background and objectives: Cigarette smoking is one of the major types of tobacco consumption seen worldwide. It contains the highest number of carcinogens and is associated with various forms of cancer. The early initiation of smoking is a cause of addiction and causing greater harm in younger population. Hence, this study aimed to evaluate the patterns of cigarette smoking and cessation perception in college students in India.

Methods: 1009 participants between the ages of 18 to 30 years were recruited in the study. Self-designed questionnaire was prepared in the form of Google forms and links were posted on social media (including Emails, Whatsapp, Instagram and Facebook).

Results: Out of 1009 participants $54.2 \%(n=547)$ 72.22\% males and $24.27 \%$ females smoked cigarettes. $68.55 \%$ smokers were between the ages of 22 to 26 years. $67.1 \%$ smoked for the first time when they were in the age group of 18 to 21 years. More than $60 \%$ were daily smokers consuming 1 to 5 cigarettes/day. 38.19 of the participants wished to stop smoking and around $62 \%$ of the participants had never made and attempt to quit. Conclusion: The present study demonstrated that more than half of Indian college students who participated in the study smoked cigarettes with the number of males being significantly higher than females. The study suggests for more tobacco prevention and cessation programs to be undertaken targeting the Indian student population leading to cancer prevention in later years of life.

KEY WORDS: Cigarette Smoking, Cessation, Students.

Address for correspondence: Dr. Renu B Pattanshetty MPT, PhD, Professor and Head, Department of Oncology Physiotherapy, KAHER Institute of Physiotherapy, Belagavi-590010, Karnataka, India. Contact no: +919448482564 E-Mail: renu_kori@rediffmail.com

Access this Article online Quick Response code

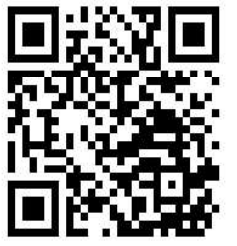

DOI: $10.16965 /$ ijpr.2021.145

Journal Information

International Journal of Physiotherapy and Research ISSN (E) 2321-1822 | ISSN (P) 2321-8975

https://www.ijmhr.org/ijpr.html

DOI-Prefix: https://dx.doi.org/10.16965/ijpr

Article Information

Received: 10 May 2021

Peer Review: 11 May 2021

Revised: None
Accepted: 14 Jun 2021

Published (O): 11 Jul 2021

Published (P): 11 Aug 2021

\section{INTRODUCTION}

Tobacco is one of the most prevalent causes of deaths worldwide leading to premature death and disease globally and also major cause for cancer [1]. Consumption of tobacco can be in various forms, that can be smoking or in smokeless form.

Tobacco in form of smoking cigarettes, Hookah, cigars, Vapor (electric cigarettes) is commonly seen in parts of Europe, America, Australia and Asia [2]. In India tobacco is smoked mainly in form of Cigarette, Hookah, Beedi or in a pipe [3]. Cigarette smoking is one major type of tobacco consumption seen worldwide. Cigarettes contain the highest number of carcinogens than any other smoked form tobacco. Therefore it is considered as the most dangerous form of tobacco consumption 
as it causes passive smoking [4].

It contains nicotine, which is addictive and it also contains more than thousand carcinogenic agents amongst which 401 are poisonous substances like cyanide and 43 are carcinogenic agents. Smoking not only harms the smoker but also the people around, like family members, co-workers, friends etc. Tobacco use is one of the most leading cause for diseases such as Chronic Obstructive Pulmonary Disease and Chronic Restrictive Pulmonary Disease [5].

Consumption of tobacco has various ill effects, including death from cancer, heart diseases, stroke and others [6]. Tobacco contains of addictive stimulant that are considered as cancer causing carcinogens which includes of alkaloid nicotine, formaldehyde, lead, arsenic, ammonia, benzene and nitrosamines. Radioactive materials in tobacco leaves is used to make cigarettes and cigars. Use of e-cigarettes is also increased in recent years, mostly in youth population. It is seen in recent studies that tobacco kills one person every six seconds worldwide [5]. The rate at which young people start smoking is very high. The youth may not be able to grasp the consequences of smoking in the long term, although significant negative health effects due to smoking and exposure to smoke have been observed.[7] According to the World Health Organization (WHO) about 5 million people all around the world die prematurely due to tobacco consumption. It is predicted that by 2030 the number of deaths caused due to tobacco consumption will rise to 10 million. [8] India is the third largest producer of tobacco in the world and is a country where tobacco is consumed in various forms.[9] The fastest rate of rise in cases of death due to tobacco consumption will be seen in India if the rate of consumption is not reduced $[5,8]$.

The patterns of smoking differ, in urban, semi-urban and rural areas and depending on the Lifestyle, profession, age, gender, etc. According to the studies the people with low economic status are less likely to be successful in attempt to quit smoking as there is less knowledge and awareness, there is less community support for quitting, less motivation from friends and family, more economical stress, and strong addiction, no available resources such as nicotine gum/ nicotine patch, etc. On the other hand, these problems are not faced by people of higher standard of living, and there is availability of resources in need therefore tobacco cessation is more likely to be successful in upper class people [2]. Cessation of smoking depends on many factors that can be personal and social. Many smokers make several attempts to quit smoking but fail to stay abstinent [10].

The early age initiation of smoking is majorly the cause for addiction effects. Research has shown that number of teens smoking cigarettes is higher than any cohort. The reason for early smoking according to recent studies are peer pressure, parental smoking habits, actors consuming tobacco and advertisements. Also there is less awareness about the harmful effects therefore tobacco cessation rate is very low in this group [11].

Addictions that are developed at a young age are mostly persist further in life. According to Indian literature very few studies have been conducted to assess the patterns and cessation of smoking perceptions in student population in India especially in college going students. Therefore this suggested a need to carry out a study to learn the pattern of smoking in student population that may further help to create awareness of health hazards related to cigarette smoking [12]. Hence, the objective of the presence study aimed to assess the patterns of cigarette smoking and cessation perception in college students in India.

\section{METHODS}

An E-survey was conducted in the month of August 2020 among college students across India. The sampling method used for recruitment was open-ended sampling for 2 weeks. Participants in the age group of 18 to 30 years were eligible for the survey and informed consent was obtained in the e-form proceeded to fill the Google Form.

\section{RESULTS}

The total number of participants in the study was 1009 out of which $63.44 \%(n=630)$ were 


\section{STROBE Flow Diagram}

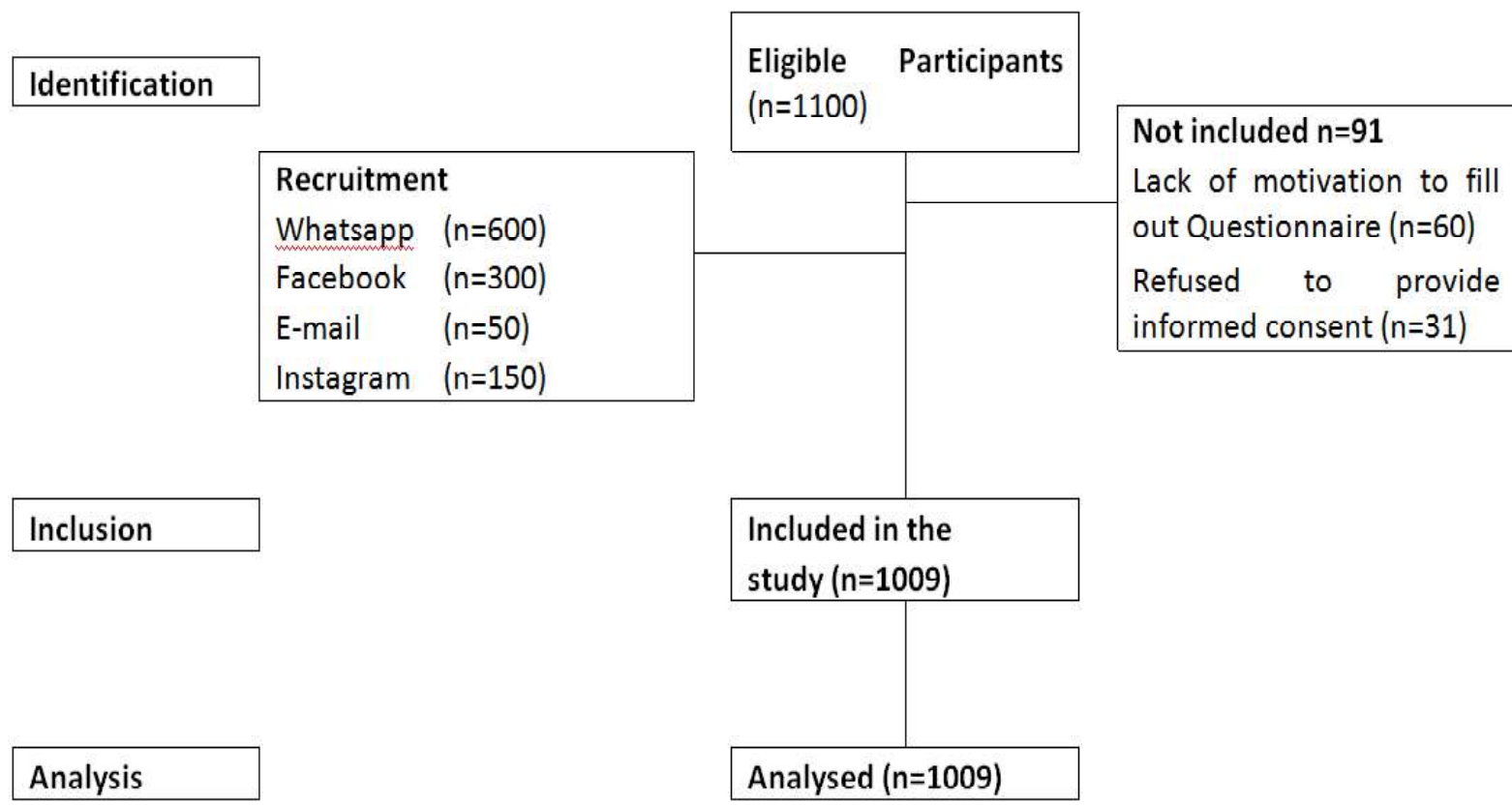

males and $37.56 \%(n=379)$ were females. Majority of the participants i.e. $57.28 \%(n=578)$ were between the ages of 22 to 26 years. $33.2 \%$ $(n=335)$ of the participants were from medical field followed by engineering field who were $32.31 \%(n=326)$ (Table 1).

Out of the 1009 participants, 54.21\% ( $n=547)$ smoked cigarettes $[n=455$ males \& $n=92$ females]. $67.09 \%(n=367)$ reported that they smoked for the first time between 18-21 years. When asked about their reasons for smoking, $31.62 \%$ participants feel the need to smoke cause they believe it helps them relieve their tension. When questioned about the frequency of smoking, $67.09 \% \quad(n=367)$ reported that they smoke daily [ $\mathrm{n}=318$ males $\& n=49$ females]. When asked about the quantity of cigarette smoking per day, $61.79 \%$ participants reported smoking 1-5 cigarettes per day (Table 2).

Amongst the total no of students who participated in the study $38.19 \%(n=270)$ students wish to stop smoking and $33.08 \%(n=239)$ do not wish to stop smoking. When questioned about attempts, $62.41 \%(n=440)$ have never tried to quit. When asked about how long they managed to remain smoke-free, $18.58 \%$ $(n=131)$ students could stay without smokingfor less than a day. When the students were questioned about methods used to quitsmoking, $26.11 \%(n=183)$ used nicotine gum/ patch. When questioned about taking help from Health care professionals $88.14 \%$ $(n=617)$ responded (Table 3$)$.

578 students belonged to the age group of 2226 years out of which 375 students were cigarette smokers $(p=0.0001)$. Out of the total participants 335 students belonged to Medical stream, out of these 87 students smoke cigarettes. 326 students belonged to Engineering out of which 216 students were smokers $(p=0.0001)$ (Table 4).

Table 1: Demographic Profile Of all the participants in the study.

\begin{tabular}{lcc}
\hline \multicolumn{1}{c}{ Gender } & Number & $\%$ \\
\hline Male & 630 & 62.44 \\
Female & 379 & 37.56 \\
Total & 1009 & 100 \\
Age & & \\
18 to 21 years & 263 & 26.07 \\
22 to 26 years & 578 & 57.28 \\
27 to 30 years & 168 & 16.65 \\
Total & 1009 & 100 \\
Education & & \\
Medical & 335 & 33.2 \\
Engineering & 326 & 32.31 \\
Architecture & 88 & 8.72 \\
Commerce & 184 & 18.24 \\
Arts & 54 & 5.35 \\
Others & 22 & 2.18 \\
Total & 1009 & 100 \\
\hline
\end{tabular}



Population in India: An E-Survey.

Table 2: Information on Cigarette smoking of all the participants in the study.
Table 3: Information on Tobacco Cessation amongst participants in the study.

\begin{tabular}{|c|c|c|c|c|c|c|}
\hline Do you smoke Cigarettes? & MALE & $\%$ & FEMALE & $\%$ & TOTAL & $\%$ \\
\hline YES & 455 & 72.22 & 92 & 24.27 & 547 & 54.2 \\
\hline NO & 175 & 27.77 & 287 & 75.72 & 462 & 45.8 \\
\hline TOTAL & 630 & & 379 & & 1009 & \\
\hline \multicolumn{7}{|l|}{ At what age did you first smoke? } \\
\hline Less than 15 years & 20 & 4.39 & 3 & 3.26 & 23 & 4.2 \\
\hline $15-17$ years & 107 & 23.51 & 20 & 21.73 & 127 & 23.2 \\
\hline $18-21$ years & 310 & 68.13 & 57 & 61.95 & 367 & 67.1 \\
\hline More than 21 years & 18 & 3.95 & 12 & 13.04 & 30 & 5.48 \\
\hline TOTAL & 455 & & 92 & & 547 & 100 \\
\hline \multicolumn{7}{|l|}{ Why do you feel the need to smoke? } \\
\hline Peer Pressure & 14 & 9.03 & 6 & 6.52 & 20 & 3.65 \\
\hline Fashion/Trend & 135 & 29.67 & 23 & 25 & 158 & 28.8 \\
\hline Fun & 113 & 24.83 & 26 & 28.26 & 139 & 25.4 \\
\hline Relieves my tension & 149 & 32.74 & 24 & 26.08 & 173 & 31.6 \\
\hline Makes me feel relaxed & 39 & 8.57 & 12 & 13.04 & 51 & 9.32 \\
\hline Other & 5 & 1.09 & 1 & 1.08 & 6 & 1.09 \\
\hline TOTAL & 455 & & 92 & & 547 & 100 \\
\hline \multicolumn{7}{|c|}{ How many days do you smoke in a month? } \\
\hline Daily & 318 & 69.89 & 49 & 53.26 & 367 & 67.1 \\
\hline Alternate Days & 62 & 13.6 & 9 & 9.78 & 71 & 13 \\
\hline Twice a week & 39 & 8.57 & 7 & 7.6 & 46 & 8.4 \\
\hline Once a week & 16 & 3.51 & 4 & 4.34 & 20 & 3.65 \\
\hline Once in 2 weeks & 3 & 0.65 & 5 & 5.43 & 8 & 1.46 \\
\hline Once a month & 15 & 3.29 & 15 & 16.3 & 30 & 5.48 \\
\hline Other & 2 & 0.43 & 3 & 3.26 & 5 & 0.91 \\
\hline TOTAL & 455 & & 92 & & 547 & 100 \\
\hline \multicolumn{7}{|c|}{ On the days that you smoke, how many cigarettes do you smoke per day? } \\
\hline Less than 1 & 44 & 9.67 & 10 & 10.3 & 54 & 9.87 \\
\hline 1 to 5 & 286 & 62.87 & 52 & 36.52 & 338 & 61.8 \\
\hline 6 to 10 & 96 & 21.09 & 22 & 23.91 & 118 & 21.6 \\
\hline 11 to 15 & 14 & 3.07 & 5 & 5.43 & 19 & 3.47 \\
\hline 16 to 20 & 2 & 0.43 & 0 & 0 & 2 & 0.36 \\
\hline More than 20 & 13 & 2.85 & 3 & 3.26 & 16 & 2.92 \\
\hline TOTAL & 455 & & 92 & & 547 & 100 \\
\hline
\end{tabular}

\begin{tabular}{|c|c|c|}
\hline Do you wish to stop smoking? & Number & $\%$ \\
\hline Yes & 270 & 38.19 \\
\hline No & 239 & 33.8 \\
\hline Don't know & 85 & 12.02 \\
\hline Later Age & 113 & 15.98 \\
\hline TOTAL & 707 & 100 \\
\hline \multicolumn{3}{|c|}{$\begin{array}{l}\text { During the past } 12 \text { months how many } \\
\text { times did you attempt to quit smoking? }\end{array}$} \\
\hline I did not try to quit & 440 & 62.41 \\
\hline 1 to 2 times & 177 & 25.11 \\
\hline 3 to 5 times & 73 & 10.35 \\
\hline 6 to 10 times & 8 & 1.13 \\
\hline More than 10 times & 7 & 0.99 \\
\hline TOTAL & 705 & 100 \\
\hline \multicolumn{3}{|c|}{$\begin{array}{l}\text { When you last tried to quit how long could } \\
\text { you stay without smoking? }\end{array}$} \\
\hline I did not try to quit & 439 & 62.27 \\
\hline Less than a day & 131 & 18.58 \\
\hline 1 to 10 days & 92 & 13.05 \\
\hline 11 to 20 days & 9 & 1.28 \\
\hline 20 to 30 days & 7 & 0.99 \\
\hline More than 30 days & 27 & 3.83 \\
\hline TOTAL & 705 & 100 \\
\hline \multicolumn{3}{|c|}{$\begin{array}{l}\text { In the past } 12 \text { months did you do any of } \\
\text { the following to help you quit using } \\
\text { smoking for good? }\end{array}$} \\
\hline I did not try to quit & 440 & 62.77 \\
\hline Used nicotine gum/nicotine patch & 183 & 26.11 \\
\hline Visited an internet quit site & 10 & 1.43 \\
\hline Got help from family or friend & 17 & 2.43 \\
\hline Tried to quit on my own & 51 & 7.28 \\
\hline TOTAL & 701 & 100 \\
\hline \multicolumn{3}{|c|}{$\begin{array}{l}\text { Have you approached any health care } \\
\text { professional to help you quit smoking? }\end{array}$} \\
\hline YES & 75 & 10.71 \\
\hline NO & 617 & 88.14 \\
\hline Doesn't Help & 8 & 1.14 \\
\hline TOTAL & 700 & 100 \\
\hline
\end{tabular}


Table 4: Association of demographic variables and the habit of smoking cigarettes of all the participants in the study.

\begin{tabular}{lcccccccc}
\hline \multicolumn{1}{c}{ Do you smoke cigarettes? } & Yes & $\%$ & No & $\%$ & Total & $\%$ & $\boldsymbol{x}^{\mathbf{2}}$ & $\mathbf{p}$-value \\
\hline Gender & & & & & & & & \\
Male & 455 & 72.22 & 174 & 27.62 & 630 & 62.43 & 220.129 & $0.0001^{*}$ \\
Female & 92 & 24.27 & 287 & 75.73 & 379 & 37.56 & & \\
Age groups & & & & & & & & \\
18-21 years & 56 & 10.23 & 207 & 44.8 & 263 & 26.06 & & \\
22- 26 years & 375 & 68.55 & 202 & 43.72 & 578 & 57.28 & 156.75 & $0.0001^{*}$ \\
27-30 years & 116 & 21.2 & 52 & 9.5 & 168 & 16.65 & & \\
Streams & & & & & & & & \\
Medical & 87 & 15.9 & 248 & 53.67 & 335 & 33.2 & & \\
Engineering & 216 & 39.48 & 110 & 23.8 & 326 & 32.3 & & \\
Architecture & 69 & 12.61 & 18 & 3.89 & 88 & 8.72 & & \\
Commerce & 137 & 25.04 & 47 & 10.17 & 184 & 18.23 & 180.763 & $0.0001^{*}$ \\
Arts & 29 & 5.3 & 25 & 5.41 & 54 & 5.35 & & \\
Others & 9 & 1.64 & 14 & 3.03 & 22 & 2.18 & & \\
Total & 547 & 100 & 462 & 100 & 1009 & 100 & \\
\hline
\end{tabular}

Level of significance- $* p<0.05$

\section{DISCUSSION}

In the present, era smoking in the Indian student population has drastically increased due to various factors. The findings of our study revealed that $54.21 \%$ of student population smoked cigarettes. According to our study maximum student belonging to age group of 22 to 26 years of age smoked the highest. Among the male student population $32.7 \%$ smoked to relieve tension and $28.6 \%$ of female population smoked for fun. Engineering students were the leading population for smoking. The most influencing factor for the student population was watching movies. Among the smokers, majority of them never made an attempt to quit.

Abigail C. Halperin et.al in their health screening survey of cigarette smoking and associated health risk among students in 5 universities founded that nearly quarter of students reported current smoking, $41 \%$ of whom reported smoking less than 1 cigarette/day and of the daily smokers $80 \%$ smoked less than 10 cigarettes/day [13]. In our study $54.21 \%$ of the students reported current smoking out of which $67.09 \%$ smoked daily, $69.79 \%$ smoked 1 to 5 cigarettes/day and $21.57 \%$ smoked 6 to 10 cigarettes/day. Only $9.87 \%$ reported consuming less than 1 cigarette/day.

Chadda RK et.al in their systematic review of tobacco use in Indian adolescent reported the prevalence of smoking in male students was $6.9 \%$ to $22.5 \%$ and in female student it was 0 to $2.3 \%$.[14] In our study of college students we found the prevalence of smoking in male students to be $72.22 \%$ and in female students it was $24.27 \%$. As our survey was among college students they are more likely to be smokers as compared to adolescents due to various factors such as comparatively less exposure, less stress etc. A comparison between both studies show a very rapid increase in the prevalence of smoking especially among males which can be attributed to the fact that males are more susceptible to peer pressure and easily influenced compared to girls.

A study conducted by David T. Levy which explored the relationship of smoking cessation to socio demographic characteristic, smoking intensity and tobacco control policies reported that younger, higher socioeconomic status and less intense daily smokers were more likely to make quit attempts [15]. Studies reported that $38 \%$ of smokers have intention to quit but only $11 \%$ had intention to quit within the next 6 months [16]. A study also reported that $70.63 \%$ of students in that study planned to be a nonsmoker in the future [17]. We explored this topic in more detail and found that $38.19 \%$ of current smokers wish to stop. Many of them tried to quit 1 to 2 times in last 12 months 
and could only stay for less than a day without smoking. Of the participants who tried to quit, most of them used nicotine gum/ patch. A vast majority i.e. $88.14 \%$ have not approached a health care professionals to help quit tobacco.

Studies have shown that multiple determinants of tobacco consumption included marriage, price, marketing strategies, socioeconomic status and population growth. Tobacco burden also included economic and social cost and the adverse health effects resulting from oral cancer. In India, in spite of tobacco control policy tobacco consumption has greatly increased and thus demonstrates a strong need of anti-tobacco campaign which includes awareness of side effects of tobacco consumption and active involvement of work sites and health professionals to promote tobacco cessation.

There is little scientifically sound evidence for pattern and cessation of smoking in student population in India additional information about side effects will be beneficial to the student population and health care providers. The present study evaluated various patterns of cigarette smoking and the need and influence of smoking in the student population. This can prove beneficial to the government or to organizations planning to conduct a tobacco cessation program or an anti-tobacco drive as this study will help them understand the specificity of the problem and will enable them to focus more resources where, deemed necessary.

The limitation of this study is that for some people the questionnaire seemed too long but it was necessary for detailed assessment and for obtaining accurate results.

\section{CONCLUSION}

In a nutshell, the survey revealed that the majority people who consumed smoked were from the age group between 22-26 years. $57.28 \%$ of the 1009 participants smoked cigarettes.

Herein, the age group that showed the extreme inclination towards smoking were participants between 22-26 years from the engineering sector. A holistic approach is of utmost importance to educate this particular age group by different ways like tobacco cessation and control programs. People should be made aware of ill-effects like oral \& throat cancer, head \& neck cancer, and lung cancer caused due to smoking.

\section{ACKNOWLEDGEMENTS}

We would like to express our gratitude to all the participants in our study.

\section{Conflicts of interest: None}

\section{REFERENCES}

[1]. Johnson N. Tobacco use and oral cancer: a global perspective. Journal of dental education. 2001;65(4):328-39.

[2]. Storr CL, Cheng $H$, Alonso J, Angermeyer $M$, Bruffaerts R, De Girolamo G, et al. Smoking estimates from around the world: data from the first 17 participating countries in the World Mental Health Survey Consortium. Tobacco control. 2010;19(1):65-74.

[3]. Chockalingam K, Vedhachalam C, Rangasamy S, Sekar G, Adinarayanan S, Swaminathan S, et al. Prevalence of tobacco use in urban, semi urban and rural areas in and around Chennai City, India. PLoS One. 2013;8(10):528-33

[4]. Shah S, Dave B, Shah R, Mehta TR, Dave R. Socioeconomic and cultural impact of tobacco in India. Journal of family medicine and primary care. 2018;7(6):1173.

[5]. Patel DN, Keny D, Mohijitsinh J, Hemanshi C, Janak D, Vikas C. A Cross sectional study of smoking among youth population. 2014;23(8):96-103

[6]. Saffer H, Chaloupka F. The effect of tobacco advertising bans on tobacco consumption. Journal of health economics. 2000;19(6):1117-37.

[7]. Singh A, Ladusingh L. Prevalence and determinants of tobacco use in India: evidence from recent Global Adult Tobacco Survey data.2014;9(12):236-38

[8]. Sharma P, Murthy P, Shivhare P. Nicotine quantity and packaging disclosure in smoked and smokeless tobacco products in India. Indian journal of pharmacology.2015;47(4):440.

[9]. Khan Z, Tönnies J, Müller S. Smokeless tobacco and oral cancer in South Asia: a systematic review with meta-analysis. Journal of cancer epidemiology. 2014;15(7):20-24

[10]. Mittal S. Smoking and Tobacco Use: III Effects on Reproductive, Maternal, Newborn, Child Health, and Adolescent (RMNCHA) Program-A Review. Annals of the National Academy of Medical Sciences (India). 2019;55(02):065-73.

[11]. Tanski SE, Prokhorov AV, Klein JD. Youth and tobacco. Minerva pediatrica. 2004;56(6):553-65.

[12]. Sharma V, Hiremath SS, Puranik M, Somasundara S. Prevalence of tobacco use among 15-20 years old college students in Bengaluru city. Journal of Indian Association of Public Health Dentistry. $2015 ; 13(1): 24$ 
[13]. Halperin AC, Smith SS, Heiligenstein E, Brown D, Fleming MF. Cigarette smoking and associated health risks among student at five universities. Nicotine \&Tobacco Research. 2010;12(2):96-104

[14]. Chadda RK, Sengupta SN. Tobacco use by Indian adolescents. Tobacco induced diseases. 2002;1(2):111.

[15]. Levy DT, Romano E, Mumford E. The relationship of smoking cessation to sociodemographic characteristics, smoking intensity, and tobacco control policies. Nicotine \&Tobacco Research. 2005; $7(3): 387-96$.
[16]. Raute LJ, Sansone G, Pednekar MS, Fong GT, Gupta PC, Quah AC, et al. Knowledge of health effects and intentions to quit among smokeless tobacco users in India: Findings from the International Tobacco Control Policy Evaluation (ITC) India Pilot Survey. Asian Pac J Cancer Prev. 2011;12(5):1233-8.

[17]. Ibrahim A, Mathew SB, Arekal SS, Kundapur R. A study to assess the awareness of ill effects of tobacco among adolescents and young adults of Mangalore. Nitte University Journal of Health Science. $2016 ; 6(3): 21$.

\footnotetext{
How to cite this article:

Renu B Pattanshetty, Lawrence Victor Fernandes, Saish Sachin Nabar, Neha Anil Yadav. Cigarette Smoking and Cessation Perception in Student Population in India: An E-Survey. Int J Physiother Res 2021;9(4):3921-3927. DOI: $10.16965 /$ ijpr.2021.145
} 